\title{
Kevin Campbell
}

The 2009 March of Dimes Prize in

Developmental Biology has been awarded jointly to Kevin Campbell of the University of lowa and to Louis Kunkel of Harvard Medical School and The Children's Hospital, Boston,

for their pioneering work in identifying the genes and proteins that are disrupted in muscular dystrophies. The prize recognizes researchers whose work has contributed to our understanding of the science that underlies birth defects. We talked to the winners about their scientific careers and their views on biomedical research. This month's interview is with Kevin Campbell, who spoke to Louisa Flintoft. The interview with Louis Kunkel will appear next month.

Your bachelor's degree is in physics. Have you found that useful as a biologist?

The problem-solving aspect is what I find really helpful today. Especially early on in your career I think it's important not to be too specialized, and having a diverse scientific background is really helpful. You never know where a research topic is going to lead.

\section{How did your work on ion channels lead to your discovery of the dystrophin-glycoprotein complex?}

When I moved to Iowa my goal was to clarify the channels involved in excitationcontraction coupling. I thought I was set and nothing would change. I sent a paper in with a grant renewal to the Muscular Dystrophy Association (MDA), and in that paper we showed that the purified ryanodine receptor was a very large protein. Don Wood, who ran the research programme at MDA, had been at a meeting where Lou Kunkel had reported the mRNA size for the gene, and it was very large. Don Wood put Lou and I together and we quickly exchanged antibodies and within 2 weeks we knew that the ryanodine receptor and dystrophin were two separate proteins. That was the beginning of my work on muscular dystrophy (MD). We probably would have given up on it, but the next summer we were trying to isolate a combined receptor complex, and it was working with the calcium channel but this other protein was coming along that wasn't working with the antibodies to the ryanodine receptor. Finally one day I stained with antibodies to dystrophin and dystrophin was there. We purified the proteins and ended up with the dystrophin-glycoprotein complex.

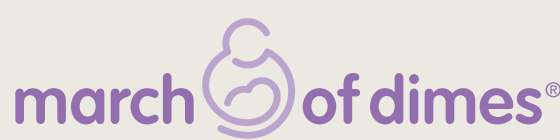

always knew patients with Becker's syndrome were missing nNOS, but a lot of people thought the fatigue was mainly due to the muscle weakness.

\section{You direct an institute that focuses on} therapeutic approaches. Does the way that biomedical research is funded encourage the clinical translation of basic research?

We're lucky in that we're very well funded. But it can be more difficult to get funding for work that's considered pure applied research. There probably needs to be new ways to evaluate that work. It can be difficult. That kind of work doesn't always lead to outstanding papers, Nature papers. Often, that work is done by companies. To get it done in academic institutions can be harder.

\section{Will traditional gene therapy live up to its potential?}

I agree with the statement of Harold Varmus that gene therapy will be used to cure disease in the next 10 to 100 years. It's obviously the way to go to put the gene back in, but it's very complicated and there are a lot of things that need to be worked out. In a number of cases, at least in the MD field, the challenge is secondary problems: delivery problems, potentially immune problems. If you put the DNA into muscle directly it incorporates it and you get a few fibres that stain quite nicely. But a few cells are not really going to help and you need to hit all the muscles. There are muscles like the diaphragm that are hard to get the gene into. So it's going to take time. In terms of other avenues, exon skipping looks very promising, and so do therapies where you allow read-through of stop codons.

\section{How important is it for you to discuss your} work with practising physicians?

Very important. We work together with physicians to try to identify new genes. At one meeting I presented a mouse model that's defective for neuronal nitric oxide synthase (nNOS) [Campbell and his group recently published a paper in Nature using mouse models, which suggests that the muscle fatigue seen in patients with neuromuscular conditions is due to defective nNOS signalling] and a physician said "They look just like my Becker patients.” That was one of several hints with that study. We

\section{Does the media report disease-related research in a useful way?}

The media is really important in getting information to the general public. Sometimes it gets inflated and that's scary. Even scientifically I think we're having a problem. If you search for "rescue for $\mathrm{mdx}$ " there are so many papers, but in most cases those are not going to be directly translated into therapies. I think that leads to a lot of people thinking that these diseases are about to be cured. I try to make sure that we don't do that. 